\title{
Salmonella in Liquid Eggs and Other Foods in Fukuoka Prefecture, Japan
}

\author{
Koichi Murakami, ${ }^{1}$ Tamie Noda, ${ }^{1,2}$ Daisuke Onozuka, ${ }^{1}$ and Nobuyuki Sera ${ }^{1}$ \\ ${ }^{1}$ Fukuoka Institute of Health and Environmental Sciences, 39 Mukaizano, Dazaifu, Fukuoka 818-0135, Japan \\ ${ }^{2}$ Chikushi Office for Health, Human Services and Environmental Issues, 3-5-25 Shirakibaru, Onojo, Fukuoka 816-0943, Japan \\ Correspondence should be addressed to Koichi Murakami; murakami@fihes.pref.fukuoka.jp
}

Received 16 July 2013; Accepted 4 September 2013

Academic Editor: Michael McClelland

Copyright (C) 2013 Koichi Murakami et al. This is an open access article distributed under the Creative Commons Attribution License, which permits unrestricted use, distribution, and reproduction in any medium, provided the original work is properly cited.

The study aimed to evaluate the prevalence of Salmonella in retail and wholesale foods in Fukuoka Prefecture, Japan. A total of 2,021 samples collected between 1999 and 2010 were tested using a culture method. Samples consisted of liquid eggs $(n=30)$, meat (beef and pork) $(n=781)$, offal $(n=69)$, processed meats $(n=2)$, seafood $(n=232)$, processed seafood (dried fish) $(n=76)$, vegetables $(n=481)$, processed vegetables $(n=87)$, fruits $(n=167)$, and herbs $(n=96)$ from 574 outlets and wholesale agents in 15 areas (five samples were undocumented regarding outlets). Overall, liquid egg showed significantly $(P<0.001)$ higher frequencies of Salmonella contamination (13.3\%) than beef $(1 / 423,0.2 \%)$ and pork (3/235, 1.3\%). Salmonella enterica subsp. enterica serovar Enteritidis, the most common serovar as a human pathogen, were isolated from two liquid egg samples. No Salmonella were isolated from seafood and vegetable-related samples including seed sprouts $(n=261)$. In conclusion, liquid egg is a significant Salmonella vehicle, showing a need to continue the vaccination of chickens to prevent $S$. Enteritidis contamination in Japanese eggs. Moreover, further study is needed to evaluate Salmonella contamination in seed sprouts with more sampling from retailers there.

\section{Introduction}

The surveillance of Salmonella in retail and wholesale foods is essential for the prevention of nontyphoidal salmonellosis, which is one of the most important problems for public health in the world [1], including Japan [2]. Salmonella frequently enter the food chain, thereby triggering either sporadic cases or outbreaks of human salmonellosis [1]. Livestock and their products are the most significant foods as vehicles of Salmonella [1,3]. In other foods, such as vegetables [4] and fish [5], Salmonella can also be present naturally and cause human salmonellosis. Recent data on the prevalence of Salmonella in retail and wholesale foods in Fukuoka Prefecture, Japan, are unavailable; therefore, surveillance is needed for reasons of public health. The aim of the present study is to evaluate the prevalence of Salmonella in retail and wholesale foods in Fukuoka Prefecture, Japan.

\section{Materials and Methods}

2.1. Sampling Area. A total of 2,021 samples were collected from Fukuoka Prefecture between May 1999 and June 2010
(Table 1). These samples consisted of liquid eggs $(n=30)$, meat (beef and pork) $(n=781)$, offal $(n=69)$, processed meats $(n=2)$, seafood $(n=232)$, processed seafood (dried fish) $(n=76)$, vegetables $(n=481)$, processed vegetables (shop-prepared salad and pickled vegetable) $(n=$ $87)$, fruits $(n=167)$, and herbs $(n=96)$. The samples were collected from 563 retail outlets and 11 wholesale agents (five samples were undocumented regarding outlets) in 15 areas of the prefecture by food hygiene inspectors from 13 health centers that are run by the Fukuoka prefectural government in May, June, July, September, October, November, and December (except for 2010). These inspectors collected foods in accordance with the collection program of the local government (http://www.pref.fukuoka.lg.jp/uploaded/life/58/ 58308 miscl.pdf, in Japanese, accessed in May 2013). The samples were kept in cool boxes with icepacks, brought to the Fukuoka Institute of Health and Environmental Sciences, and tested within $6 \mathrm{~h}$ of collection. Fukuoka Prefecture is located in Kyushu, the main southwestern island of Japan. In 2010, the entire population of the prefecture was 5,071,968 and that of the 15 sampling areas was 2,507,741. 
TABLe 1: Prevalence of Salmonella in retail food samples from Fukuoka Prefecture.

\begin{tabular}{|c|c|c|c|c|c|c|c|c|c|c|c|c|c|}
\hline \multirow{2}{*}{ Samples } & \multicolumn{13}{|c|}{ Number of samples tested by year } \\
\hline & 1999 & 2000 & 2001 & 2002 & 2003 & 2004 & 2005 & 2006 & 2007 & 2008 & 2009 & 2010 & Total \\
\hline Meat, offal, and processed meat & 65 & 60 & $87(1)^{\dagger}$ & $73(2)$ & 73 & 76 & $81(1)$ & 76 & $83(1)$ & $78(1)$ & 78 & 22 & $852(6)^{\S}$ \\
\hline Liquid eggs & 0 & 0 & 0 & 0 & 0 & 0 & 5 & $5(1)^{\ddagger}$ & 5 & $5(1)$ & $5(1)$ & $5(1)$ & $30(4)^{* *}$ \\
\hline Seafood and processed seafood* & 55 & 30 & 30 & 30 & 25 & 25 & 20 & 20 & 20 & 20 & 23 & 10 & 308 \\
\hline \multirow[t]{2}{*}{$\begin{array}{l}\text { Vegetables, processed vegetables, } \\
\text { fruits, and herbs }{ }^{*}\end{array}$} & 70 & 90 & 80 & 80 & 70 & 70 & 75 & 75 & 75 & 75 & 71 & 0 & 831 \\
\hline & 190 & 180 & 197 & 183 & 168 & 171 & 181 & 176 & 183 & 178 & 177 & 37 & 2,021 \\
\hline
\end{tabular}

${ }^{*}$ No Salmonella were isolated from seafood, processed seafood, vegetables, processed vegetables, fruit, and herbs.

${ }^{\dagger}$ Number of Salmonella-positive samples.

${ }^{\ddagger}$ In liquid eggs, Salmonella enterica subsp. enterica serovar (S.) Enteritidis were isolated in 2006 and 2009. S. Montevideo and S. Braenderup were also isolated in 2008 and 2010, respectively.

${ }^{\S}$ Meat, offal, and processed meat samples harbored significantly more Salmonella than the seafood and processed seafood samples $(P<0.001)$; there was no difference in the incidence of Salmonella between the meat, offal, and processed meat samples and vegetable, processed vegetable, fruit, and herb samples $(P=$ 0.503).

${ }^{* *}$ Liquid egg samples harbored significantly more Salmonella than the other three groups of samples $(P<0.001)$.

TABLE 2: Salmonella-positive rates among meat, offal, and processed meat samples.

\begin{tabular}{|c|c|c|c|c|}
\hline Meat and offal & $\begin{array}{c}\text { Number of } \\
\text { samples }\end{array}$ & $\begin{array}{c}\text { Number of } \\
\text { Salmonella-positives } \\
(\%)\end{array}$ & Serovars isolated & $\begin{array}{c}P \text { values obtained from } \\
\text { two-sample tests for proportions } \\
\text { between each sample and liquid } \\
\text { egg sample }\end{array}$ \\
\hline Beef meat & 423 & $1(0.2 \%)$ & S. Infantis* (in 2008) & $<0.001$ \\
\hline Cattle offal & 68 & $1(1.5 \%)$ & S. Corvallis and O-untypeable (in 2007) & 0.014 \\
\hline $\begin{array}{l}\text { Processed beef (roast } \\
\text { beef) }\end{array}$ & 2 & $0(0.0 \%)$ & & 0.581 \\
\hline Pork meat & 235 & $3(1.3 \%)$ & $\begin{array}{l}\text { S. Infantis (in } 2001 \text { and 2002), } \\
\text { O-untypeable (in 2002) }\end{array}$ & $<0.001$ \\
\hline $\begin{array}{l}\text { Mixed minced beef and } \\
\text { pork }\end{array}$ & 58 & $1(1.7 \%)$ & S. Typhimurium (in 2005) & 0.026 \\
\hline Unrecorded offal & 1 & $0(0.0 \%)$ & & $\begin{array}{l}\text { Number of samples } \\
\text { insufficient for analysis }\end{array}$ \\
\hline Unrecorded meat & 65 & $0(0.0 \%)$ & & 0.003 \\
\hline Total & 852 & $6(0.7 \%)$ & & \\
\hline
\end{tabular}

${ }^{*}$ S., Salmonella enterica subsp. enterica serovar.

2.2. Meat, Giblets, Offal, and Processed Meat Samples. A total of 852 samples, consisting of beef meat, beef offal, processed beef (roast beef), pork meat, mixed minced beef and pork, unrecorded offal, and unrecorded meat (Tables 1 and 2), were collected from 362 outlets. In 2004, there were, in total, 2,812 meat outlets in these sampling areas (data from the Fukuoka prefectural government).

2.3. Liquid Egg Samples. The samples $(n=30)$ were collected from 11 wholesale agents between 2005 and 2010 (Table 1). Two of the 11 wholesale agents were also the only manufacturers of liquid eggs in this sampling area.

2.4. Seafood and Processed Seafood Samples. A total of 308 samples are described in Table 3. 306 of these samples were collected from 149 outlets (Table 1) with the source of two other samples undocumented. In 2004, there were a total of 2,615 seafood outlets in these sampling areas (data from the
Fukuoka prefectural government) but no data were available on the number of processed seafood outlets.

2.5. Vegetable, Processed Vegetable, Fruit, and Herb Samples (Vegetable-Related Samples). A total of 831 samples are described in Table 3. Almost all of these samples (828 out of 831) were collected from 205 outlets between 1999 and 2009 (Table 1), with the source of three samples undocumented. In 2006 , there were a total of 4,379 vegetable and fruit outlets in these sampling areas (estimated data from the Fukuoka prefectural government).

2.6. Salmonella Investigation. Samples were tested for Salmonella using a culture method. Samples $(25 \mathrm{~g})$ in $225 \mathrm{~mL}$ of buffered peptone water (Oxoid Ltd., Basingstoke, UK) were homogenized for one minute in stomachers (Seward Ltd., Sussex, UK) and incubated at $35^{\circ} \mathrm{C}$ for $18 \mathrm{~h}$. For testing liquid egg, melanterite $(64 \mathrm{mg} / \mathrm{L})$ was added to the buffered peptone 
TABLE 3: Seafood- and vegetable-related samples (no samples harbored Salmonella).

(a)

\begin{tabular}{|c|c|c|}
\hline $\begin{array}{l}\text { Seafood and processed } \\
\text { seafood samples }\end{array}$ & Details & $\begin{array}{c}\text { Number } \\
\text { of } \\
\text { samples }\end{array}$ \\
\hline Beloniformes $(n=2)$ & Saury pike & 2 \\
\hline Clupeiformes $(n=1)$ & Sardine & 1 \\
\hline Gadiformes $(n=1)$ & Cod & 1 \\
\hline Mugiliformes $(n=2)$ & Bora & 2 \\
\hline Myliobatiformes $(n=1)$ & Whip ray & 1 \\
\hline \multirow[t]{17}{*}{ Perciformes $(n=185)$} & Amberjack & 33 \\
\hline & Big-eyed tuna & 1 \\
\hline & Common sea bass & 7 \\
\hline & Dorado & 3 \\
\hline & Hair tail & 2 \\
\hline & Horse mackerel & 12 \\
\hline & Mackerel & 7 \\
\hline & Redfish & 1 \\
\hline & Sea bream & 73 \\
\hline & Skipjack (bonito) & 2 \\
\hline & Striped horse mackerel & 1 \\
\hline & Striped pigfish & 2 \\
\hline & Swordfish & 1 \\
\hline & Tilefish & 1 \\
\hline & Tuna & 4 \\
\hline & White croaker & 1 \\
\hline & Yellowtail & 34 \\
\hline \multirow[t]{2}{*}{ Pleuronectiformes $(n=14)$} & Bastard halibut & 12 \\
\hline & Flat fish & 2 \\
\hline \multirow[t]{3}{*}{ Salmoniformes $(n=11)$} & Atlantic salmon & 6 \\
\hline & Coho salmon & 2 \\
\hline & Salmon & 3 \\
\hline \multirow[t]{2}{*}{ Scorpaeniformes $(n=2)$} & Black cod & 1 \\
\hline & Flathead & 1 \\
\hline \multirow[t]{3}{*}{ Other seafood $(n=13)$} & Scallop & 1 \\
\hline & Squid & 8 \\
\hline & Shrimp & 4 \\
\hline \multirow[t]{2}{*}{ Processed seafood $(n=76)$} & Dried fish & 76 \\
\hline & Total & 308 \\
\hline
\end{tabular}

(b)

\begin{tabular}{lcc}
\hline $\begin{array}{l}\text { Vegetable, processed } \\
\text { vegetable, fruit, and herb } \\
\text { samples }\end{array}$ & Details & $\begin{array}{c}\text { Number } \\
\text { of } \\
\text { samples }\end{array}$ \\
\hline $\begin{array}{l}\text { Bulb and stem vegetables } \\
(n=5)\end{array}$ & Celery & 2 \\
& $\begin{array}{c}\text { Leek } \\
\text { Welsh onion }\end{array}$ & 1 \\
\hline $\begin{array}{l}\text { Leafy and salad vegetables } \\
(n=201)\end{array}$ & Cabbage & 16 \\
& $\begin{array}{c}\text { Chinese cabbage } \\
\text { Green lettuce }\end{array}$ & 39 \\
\hline
\end{tabular}

(b) Continued.

\begin{tabular}{|c|c|c|}
\hline $\begin{array}{l}\text { Vegetable, processed } \\
\text { vegetable, fruit, and herb } \\
\text { samples }\end{array}$ & Details & $\begin{array}{l}\text { Number } \\
\text { of } \\
\text { samples }\end{array}$ \\
\hline & Leaf lettuce & 11 \\
\hline & $\begin{array}{c}\text { Leaf of daikon (white } \\
\text { radish) }\end{array}$ & 1 \\
\hline & Lettuce & 101 \\
\hline & Nozawana (turnip greens) & 1 \\
\hline & Potherb mustard & 3 \\
\hline & Red leaf lettuce & 5 \\
\hline & Spinach & 23 \\
\hline \multirow[t]{3}{*}{$\begin{array}{l}\text { Root and tuberous } \\
\text { vegetables }(n=14)\end{array}$} & Carrot & 1 \\
\hline & Daikon (white radish) & 10 \\
\hline & Turnip & 3 \\
\hline \multirow[t]{5}{*}{ Seed sprouts $(n=261)$} & Alfalfa & 5 \\
\hline & Bean sprout & 122 \\
\hline & Broccoli sprout & 7 \\
\hline & Japanese radish sprout & 126 \\
\hline & Mustard sprout & 1 \\
\hline \multirow{2}{*}{$\begin{array}{l}\text { Processed vegetables } \\
(n=87)\end{array}$} & Shop-prepared salad & 74 \\
\hline & Pickled vegetable & 13 \\
\hline \multirow[t]{3}{*}{ Fruits $(n=167)$} & Cucumber & 105 \\
\hline & Eggplant & 8 \\
\hline & Tomato & 54 \\
\hline \multirow[t]{4}{*}{ Herbs $(n=96)$} & Japanese honeywort & 93 \\
\hline & Myoga (ginger) & 1 \\
\hline & Parsley & 2 \\
\hline & Total & 831 \\
\hline
\end{tabular}

water. After incubation, $0.5 \mathrm{~mL}$ aliquots of the preenriched test liquid egg portions were subcultured in parallel both in a tube with $10 \mathrm{~mL}$ of Rappaport-Vassiliadis enrichment broth (Oxoid Ltd.) and in a tube with $10 \mathrm{~mL}$ of tetrathionate broth (Oxoid Ltd.) in accordance with a Japanese law, The Food Sanitation Act (http://www.japaneselawtranslation.go.jp/law/ detail_main?vm=\&id=12, accessed in July 2013). Samples other than liquid egg were tested using the same methods as liquid egg from the beginning of the project in 1999 to September 24, 2006, $(n=1,398)$. From September 25, 2006 , to the end of the project in $2010,0.1 \mathrm{~mL}$ aliquots of the preenriched test portions of samples other than liquid egg were added to the Rappaport-Vassiliadis enrichment broth and $1 \mathrm{~mL}$ aliquots were also added to the tetrathionate broth $(n=1,084)$, in accordance with a Japanese standard method NIHSJ-01 (National Institute of Health Sciences, http://www.nihs.go.jp/fhm/kennsahou-index.html, accessed in August 2012). These cultures were selectively enriched at $42^{\circ} \mathrm{C}$ for $18 \mathrm{~h}$. The cultures were then streaked for isolation on differential plating media, using two SMID agar (bioMérieux, Lyon, France) and two XLT4 agar plates (BD Diagnostic Systems, Sparks, Maryland, USA). From October to December 2009, CHROMagar Salmonella (Chromagar, Paris, France) and DHL agar (Eiken Chemical Co., Tokyo, Japan) 
were used instead of SMID and XLT4, in accordance with method NIHSJ-01. The plates were incubated at $35^{\circ} \mathrm{C}$ for $18-$ $48 \mathrm{~h}$. Suspected Salmonella colonies (1-4 colonies/sample) were then profiled biochemically as described by Murakami et al. [6]. Isolates with a profile consistent with Salmonella were serotyped using somatic and flagella antisera (Denka Seiken Co., Tokyo, Japan).

2.7. Statistical Analysis. Statistical analyses were carried out with two-sample tests for proportions using SAS Software, version 9.1.3 (SAS Institute Inc., Cary, NC, USA) with any test showing $P<0.01$ being considered as statistically significant.

\section{Results and Discussion}

Table 1 shows the prevalence of Salmonella in retail and wholesale samples of meat, offal, and processed meats. Samples of beef meat (1/423), cattle offal, (1/68), pork meat $(3 / 235)$, and mixed minced beef and pork (1/58) were contaminated with Salmonella (Table 2). Salmonella were also isolated from four of 30 liquid egg samples, showing that the samples harbored significantly more Salmonella $(P<$ $0.001)$ than the other groups of samples in Table 1 and both beef pork samples in Table 2. The Salmonella consisted of Salmonella enterica subsp. enterica serovar (S.) Enteritidis $(n=2)$ in 2006 and 2009, S. Montevideo $(n=1)$ in 2008, and S. Braenderup $(n=1)$ in 2010. However, no Salmonella were isolated from seafood, processed seafood, or vegetablerelated samples (Table 1 ).

In this study we have shown that liquid egg samples showed significantly higher frequencies of Salmonella contamination (13.3\%) than beef $(0.2 \%)$ and pork (1.3\%) samples whereas seafood, processed seafood, vegetable, processed vegetable, fruit, and herb samples harbored no Salmonella. The samples tested, except for the liquid egg and dried fish samples, might possibly be representative of the foods in the sampling areas because the proportion of outlets tested in the long term study, $12.9 \%(362 / 2,812)$ for meat outlets and $5.7 \%(149 / 2,615)$ for seafood outlets, was higher than $4.7 \%$ $(205 / 4,379)$ for vegetable and fruit outlets that had the lowest level of coverage.

These results on contamination levels in retail and wholesale food samples have been compared with other studies. The results for liquid egg (13.3\%) were comparable to those from our previous study (18.6\%) in 1995-1998 [6]. Namimatsu et al. [7] reported that $30.2 \%$ of 53 Japanese liquid egg samples were contaminated with Salmonella (sampling years were undocumented). Ohtsuka et al. [8] also reported a high frequency of Salmonella in Japanese liquid eggs (78.6\%-100\% from 24-28 samples) from four manufacturers in 2003. The chicken egg is one of the most important infection sources of $S$. Enteritidis, the most common serovar as a human pathogen [1]. Vaccinations are carried out to prevent $S$. Enteritidiscontamination in Japanese eggs [9]. According to Esaki et al. [10], vaccination played an important role in reducing the Salmonella contamination levels in eggs from 0.03\% (1990$1992)$ to $0.003 \%$ (2010-2011). Our results show the need for further programs of vaccination.
The results for pork (1.3\%) were also comparable to those from other studies: 0\% in Fukuoka, Japan, in 19951998 [6], 3.8\% in a nationwide study in Japan on ground pork from 2000 to 2008 [11], 1.9\% in the United Kingdom from 2003 to 2005 [12], and 3.2\% in Japan (sampling years were undocumented) [13]. The contamination frequency for Salmonella in beef $(0.2 \%)$ was comparable to those in a nationwide study in Japan from 2000-2008 (1.5\% in ground beef) [11], the UK $(1.1 \%, 18 / 1514)$ in 2003 to 2005 [12], and the USA (1.9\%) in 1999-2000 [14]. As many other reports have evaluated contamination in minced beef [15], these values are not comparable with those from the present study. Seafood Salmonella contamination has been reported in China (20.8\%) in 2005 [16] while no Salmonella were detected from seafood in this study. Of course, when comparing our results with previous studies, we must take into account several factors, such as differences in sampling procedures, origin, age of the animals at slaughter, and level of sanitation $[17,18]$. Therefore, we are unable to compare them directly. Despite this, we believe that the frequency of contaminated beef $(0.2 \%)$ and pork $(1.3 \%)$ in the present study cannot be interpreted as a high frequency.

Vegetables, especially seed sprouts, have often harbored Salmonella $[19,20]$, whereas no Salmonella were isolated from vegetables including seed sprouts $(n=261)$ in this study. However, other studies have shown Salmonella contamination in seed sprouts: Fahey et al. [21] tested seed sprout samples and only 24 (0.75\%) of the 3191 samples (in 2001) gave a positive response for Escherichia coli or Salmonella. Another study in Japan has also shown a low frequency of Salmonella in seed sprouts: only seven samples (0.1\%) from 4,848 seed sprout samples harbored Salmonella between 1998 and 2008 [11]. Therefore, further study is required to evaluate Salmonella contamination in seed sprouts by collecting more samples in Fukuoka Prefecture, Japan.

\section{Conclusion}

Liquid egg is an important Salmonella vehicle, showing significantly higher frequencies of contamination $(13.3 \%)$ compared with pork $(1.3 \%)$ and beef $(0.2 \%)$ in the present study $(P<0.001)$. Seafood, processed seafood, vegetable, processed vegetable, fruit, and herb samples harbored no Salmonella whereas further study is needed to evaluate Salmonella contamination in seed sprouts with a further collection of samples in Fukuoka Prefecture, Japan. Our results also show the need to continue the vaccination of chickens to prevent $S$. Enteritidis contamination in Japanese eggs.

\section{Conflict of Interests}

The authors declare that there is no conflict of interests.

\section{Acknowledgments}

This work was supported in part by the Daido Life Welfare Foundation, Osaka, Japan. The authors thank the food 
hygiene inspectors and veterinarians of the Fukuoka Prefectural Government for collecting the samples and for their advice. The authors also thank Dr. Hirata, Dr. Ishiguro, Dr. Chijiw, Dr. Horikawa, and Dr. Takenaka of the Fukuoka Institute of Health and Environmental Sciences for their invaluable advice. The authors thank Dr. Saeki, Mr. Nagano, Mr. Hamasaki, Mr. Etoh, Dr. Ichihara, Mr. Kimoto, and Ms. Uemura for their technical assistance.

\section{References}

[1] T. Humphrey, "Public health aspects of Salmonella enterica in food production," in Salmonella Infections, Clinical, Immunological and Molecular Aspects, P. Mastroeni and D. Maskell, Eds., pp. 89-116, Cambridge University Press, Cambridge, UK, 2006.

[2] K. Murakami, T. Ishihara, K. Horikawa, and T. Oda, "Features of Salmonella serovars among food handlers in Kyushu, Japan," New Microbiologica, vol. 30, no. 2, pp. 155-159, 2007.

[3] Food and Agriculture Organization of the United Nations and the World Health Organization, "Salmonella and Campylobacter in chicken meat," in Microbiological Risk Assessment Series, p. 51, WHO Press, Geneva, Switzerland, 2009.

[4] S. Werner, K. Boman, I. Einemo et al., "Outbreak of Salmonella Stanley in Sweden associated with alfalfa sprouts, July-August 2007," Euro surveillance, vol. 12, no. 10, p. E071018.2, 2007.

[5] H. S. Kumar, R. Sunil, M. N. Venugopal, I. Karunasagar, and I. Karunasagar, "Detection of Salmonella spp. in tropical seafood by polymerase chain reaction," International Journal of Food Microbiology, vol. 88, no. 1, pp. 91-95, 2003.

[6] K. Murakami, K. Horikawa, T. Ito, and K. Otsuki, "Environmental survey of Salmonella and comparison of genotypic character with human isolates in Western Japan," Epidemiology and Infection, vol. 126, no. 2, pp. 159-171, 2001.

[7] T. Namimatsu, M. Tsuna, Y. Imai et al., "Detection of Salmonella by using the colorimetric DNA/rRNA sandwich hybridization in microtiter wells," Journal of Veterinary Medical Science, vol. 62, no. 6, pp. 615-619, 2000.

[8] K. Ohtsuka, K. Yanagawa, K. Takatori, and Y. Hara-Kudo, "Detection of Salmonella enterica in naturally contaminated liquid eggs by loop-mediated isothermal amplification, and characterization of Salmonella isolates," Applied and Environmental Microbiology, vol. 71, no. 11, pp. 6730-6735, 2005.

[9] Y. Toyota-Hanatani, T. Ekawa, H. Ohta et al., "Public health assessment of Salmonella enterica serovar Enteritidis inactivated-vaccine treatment in layer flocks," Applied and Environmental Microbiology, vol. 75, no. 4, pp. 1005-1010, 2009.

[10] H. Esaki, K. Shimura, Y. Yamazaki, M. Eguchi, and M. Nakamura, "National surveillance of Salmonella enteritidis in commercial eggs in Japan," Epidemiology and Infection, vol. 141, no. 5, pp. 941-943, 2013.

[11] Y. Hara-Kudo, H. Konuma, Y. Kamata et al., "Prevalence of the main food-borne pathogens in retail food under the national food surveillance system in Japan," Food Additives \& Contaminants A, vol. 30, no. 8, pp. 1450-1458, 2013.

[12] C. L. Little, J. F. Richardson, R. J. Owen, E. de Pinna, and E. J. Threlfall, "Campylobacter and Salmonella in raw red meats in the United Kingdom: prevalence, characterization and antimicrobial resistance pattern, 2003-2005," Food Microbiology, vol. 25, no. 3, pp. 538-543, 2008.

[13] M. Tokumaru, H. Konuma, M. Umesako, S. Konno, and K. Shinagawa, "Rates of detection of Salmonella and Campylobacter in meats in response to the sample size and the infection level of each species," International Journal of Food Microbiology, vol. 13, no. 1, pp. 41-46, 1991.

[14] C. Zhao, B. Ge, J. De Villena et al., "Prevalence of Campylobacter spp., Escherichia coli, and Salmonella serovars in retail chicken, turkey, pork, and beef from the greater Washington, D.C., Area," Applied and Environmental Microbiology, vol. 67, no. 12, pp. 5431-5436, 2001.

[15] J. R. Rhoades, G. Duffy, and K. Koutsoumanis, "Prevalence and concentration of verocytotoxigenic Escherichia coli, Salmonella enterica and Listeria monocytogenes in the beef production chain: a review," Food Microbiology, vol. 26, no. 4, pp. 357-376, 2009.

[16] H. Yan, L. Li, M. J. Alam, S. Shinoda, S. I. Miyoshi, and L. Shi, "Prevalence and antimicrobial resistance of Salmonella in retail foods in northern China," International Journal of Food Microbiology, vol. 143, no. 3, pp. 230-234, 2010.

[17] P. Antunes, C. Réu, J. C. Sousa, L. Peixe, and N. Pestana, "Incidence of Salmonella from poultry products and their susceptibility to antimicrobial agents," International Journal of Food Microbiology, vol. 82, no. 2, pp. 97-103, 2003.

[18] F. L. Bryan and M. P. Doyle, "Health risks and consequences of Salmonella and Campylobacter jejuni in raw poultry," Journal of Food Protection, vol. 58, no. 3, pp. 326-344, 1995.

[19] C. J. Gill, W. E. Keene, J. C. Mohle-Boetani et al., "Alfalfa seed decontamination in a Salmonella outbreak," Emerging Infectious Diseases, vol. 9, no. 4, pp. 474-479, 2003.

[20] P. J. Taormina, L. R. Beuchat, and L. Slutsker, "Infections associated with eating seed sprouts: an international concern," Emerging Infectious Diseases, vol. 5, no. 5, pp. 626-634, 1999.

[21] J. W. Fahey, P. J. Ourisson, and F. H. Degnan, "Pathogen detection, testing, and control in fresh broccoli sprouts," Nutrition Journal, vol. 5, article 13, 2006. 

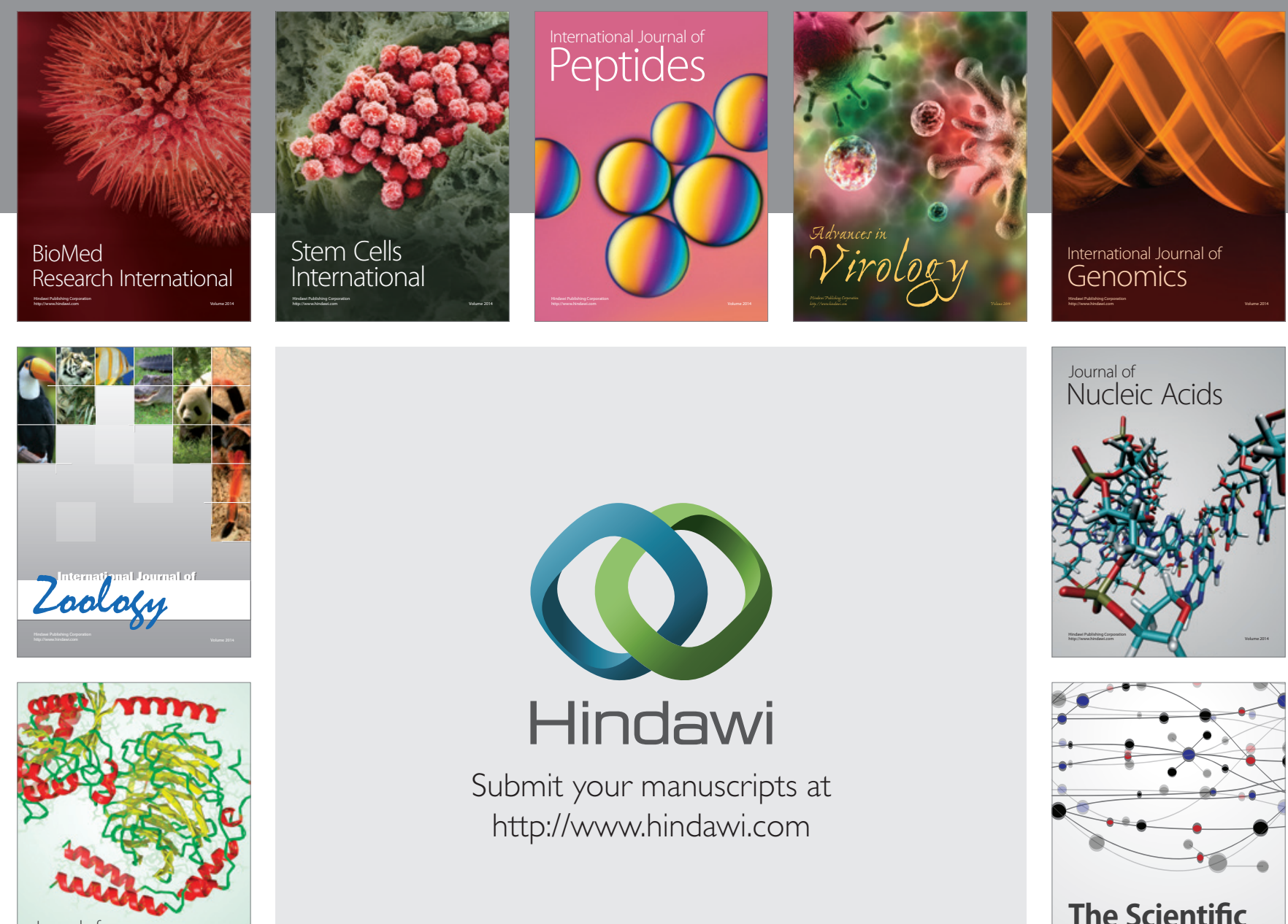

Submit your manuscripts at

http://www.hindawi.com

Journal of
Signal Transduction
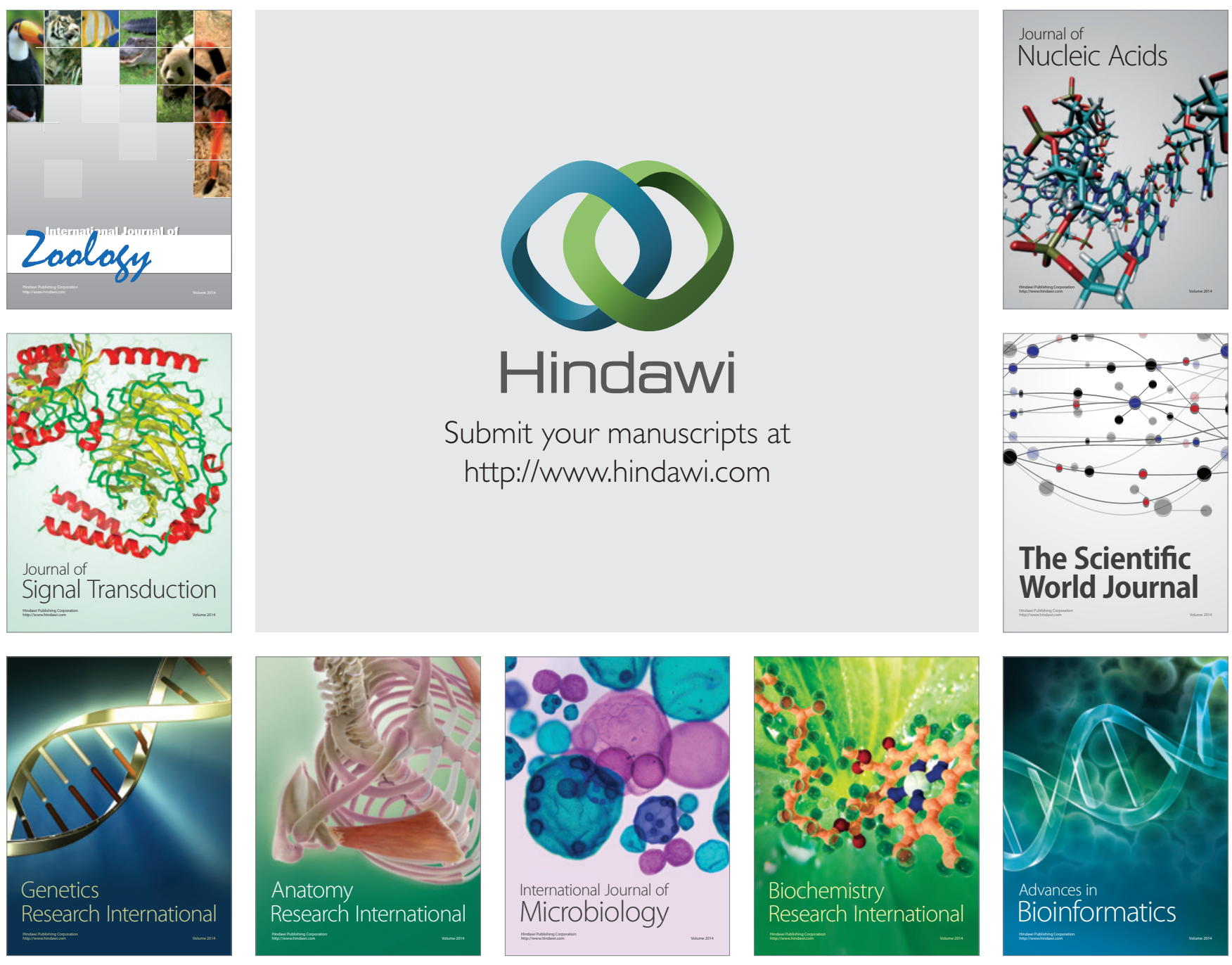

The Scientific World Journal
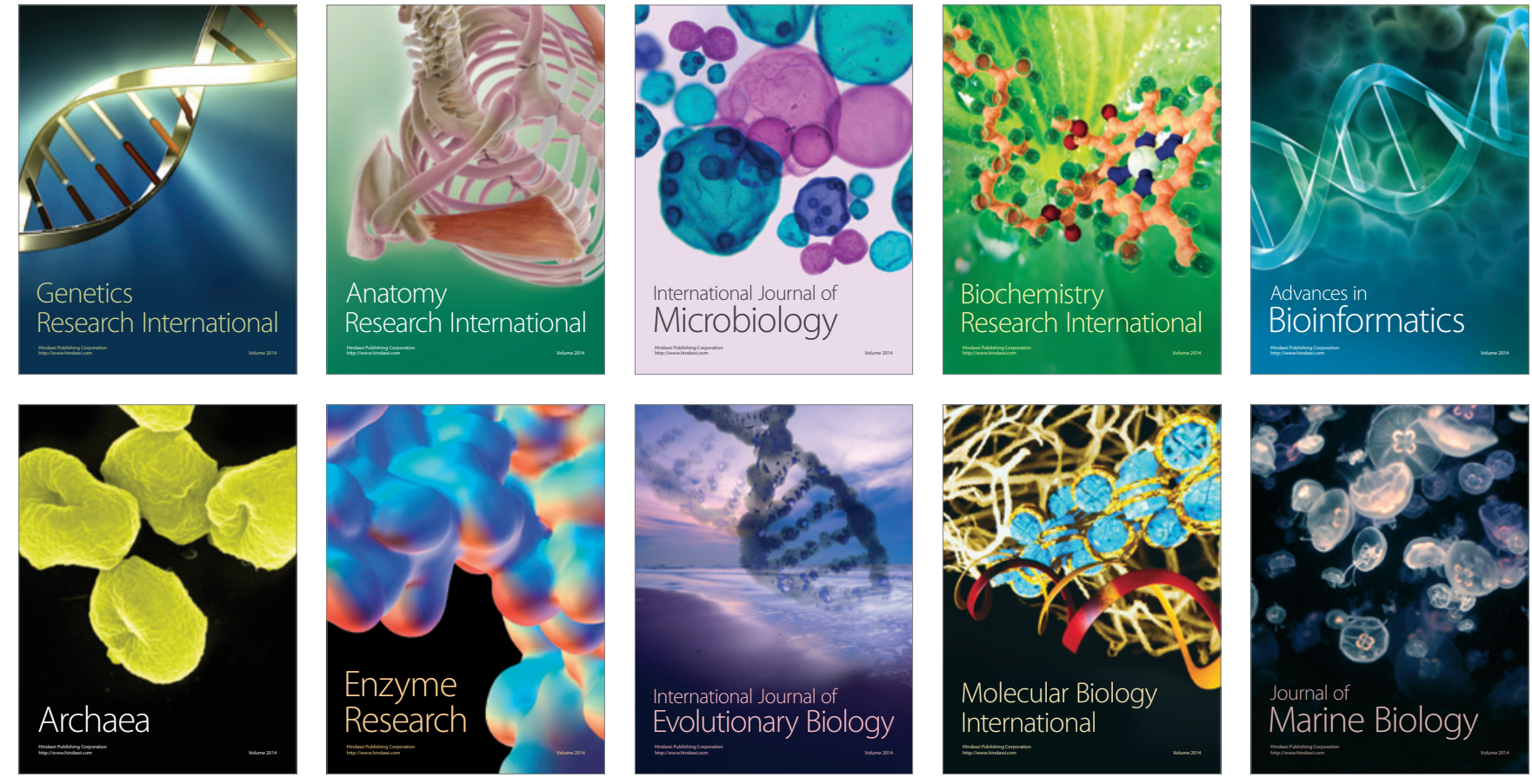